\title{
Failure Modes Analysis of Stone Arch Bridges
}

\author{
Song Jun ${ }^{*}, 1$, Wang Fumin ${ }^{2}$, and Shi Kang ${ }^{3}$ \\ ${ }^{1}$ School of Civil Engineering, SongJun, Ludong University, Yantai, China \\ ${ }^{2}$ Fund of National Engineering and Research Center for Mountainous Highways, Wang Fumin, Chongqing, China \\ ${ }^{3}$ School of Civil Engineering, Shi Kang Central South University, Changsha, China
}

\begin{abstract}
A destruction test based on the bridge safety appraisal is one way to verify the failure law of an actual bridge. In this paper, a stone arch bridge in a 1:10 scale model and with a span of $60 \mathrm{~m}$ (namely, an arch bar of the same length as the object of test) has been tested, methods of its whole test and loading process introduced, and ultimate bearing capacity, deflection and development rules of cracks in the loading process figured out. With the clarification of destruction mechanism, the ultimate forms of disease and remaining height of section have been acquired and, finally, the destruction theory of stone arch bridges has been verified and optimized.
\end{abstract}

Keywords: Destruction Test, scale model, stone arch bridge.

\section{INTRODUCTION}

In this paper, the safety appraisal of a stone arch bridge has been achieved through an overall destruction test. As the main arch ring is the most important structure to the bridge as the heart to a person, so experts and scholars, in recent years, have mainly focused on its destruction in research of destruction morphology. However, the existing analysis of such a bridge is restricted to the elastic stage only. And it is this stage that the bearing capacity of the main arch with cracks, weathering and cavities is calculated so as to estimate the safety of the bridge. The present standard, "JTG H112004" also estimates the danger degrees of bridges from its levels of cracks and cavities, yet it depends mostly on experts' experience, which is quite conservative. According to the authors, the pulp block stone, as an elastic-plastic material, is of great necessity to be used for the safety assessment of the main arch as a compression-bending structure, plastic hinges are likely to form in the main arch as the plastic zone appears. Once a structure is loaded, there exists a point where fiber yield appears on relative surface but is not broken, and this very point is considered as a plastic hinge. As a result, one component is divided into two parts and one plastic hinge, and both parts can rotate around the plastic hinge, that is to say, one constraint is reduced. Right then, the destruction types of the main arch ring in and outside China are mainly concentrated on the four- hinge destruction theory, and has made great progress [1-4].

Condition assessment of masonry arch bridges generally relies on visual observation and on a limited range of diagnostic techniques, including destructive and nondestructing testing and monitoring methods [5]. Foreign

*Address correspondence to this author at the School of Civil Engineering, Ludong University, Yantai 264025, People's Republic of China;

Tel/Fax: 008613021617898; 008605356697523;

E-mail: songjun198298@163.com researchers have done many bridge damage test [6-10], for example, DesMoines River truss bridge ultimate load bearing capacity test, compared with theory and load test results, A retired Reinforced Concrete slab bridge is made a destructive test in the United States, it is proved that the elastic properties of the bridge without deterioration, but deteriorated dramatically reduces the carrying capacity of the bridge, and the Stoney Creek bridge has a destructive test, the experiment was designed to study the bridge in the limit state under lateral load distribution form. But these achievements are not discussed the relationship between the development of crack and bearing capacity of the structure. Based on the crack evaluation coefficient, experience formula is presented in this paper which is filled the gaps in the relevant field.

Section cracking should be the premise of the plastic hinge formation, and its process is also that of appearance and development of cracks. But, different people have given different conclusions about how to define to the plastic hinge as the section cracking goes on [11-15]. However, as the conclusions are based on quite unreasonable assumptions, thus appear exist plenty of limitations. In order to get the failure process characteristics of a stone arch bridge, research on its destruction types by a model test and safety appraisal must be done.

\section{DISCUSSION OF SAFETY APPRAISAL PATTERN}

\subsection{Failure Pattern Analysis}

This section provides details of the methodology used along with information on any previous efforts with corresponding references. Any details for further modifications and research should be included.

As the main arch ring is so important to the stone arch bridge, it can be safely said that if a minute analysis of its 
destruction types is a must. That is why domestic and foreign experts and scholars have been mostly concentrated on the destruction types while analyzing failure patterns.

Institutional analysis was first proposed in 1712 by Le Hire [16, 17], and the modern institutional method was put forward in 1982 by Cambridge engineering professor Dean Heyman, who, with a view to the elastic-plastic performance of masonry materials, believes that cracks brought by loads (including support displacement) makes three or more hinges to a hingeless arch bridge, which is the critical reason of destruction. His main assumptions are that: a) the paving seam between two blocks has no capability to resist tensile stress; b) the paving seam between two blocks could transfer infinite pressure stress and; c) shearing is unlikely to occur between two blocks.

It is Heyman's belief that, when the bridge is under load, the pressure line of the arch ring would not exceed the arch ring as the internal force has to balance the external force. When the pressure line intersects or is tangential to the inner or outer edge of the arch ring, a plastic hinge shows at that very point. For a hingeless arch, if plastic hinges exceeds three, it means that the arch bridge, which has changed into the mechanism system from a three- statically- indeterminate structure, has reached its limit state (see Fig. 1 on the left). Hinges appear at points A, B and C, with its shape of shown on the right side of Fig. (1).
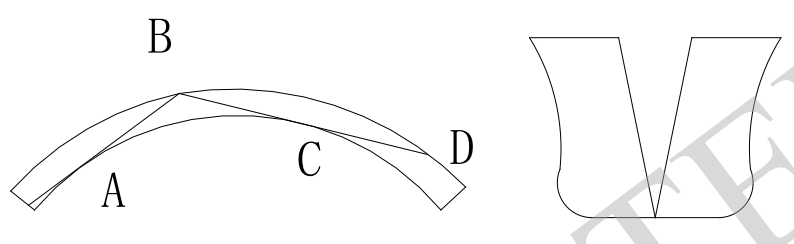

Fig. (1). Shape of a hinge at where a plastic hinge forms

Divide the bridge into 12 parts with its vault load equivalents at the node (as shown in Fig. 2). Take three plastic hinges from the structure by means of plastic hinge moment balance, and the ultimate load can be calculated. This method helps to determine which variables and what limit states are related and which variables are otherwise.

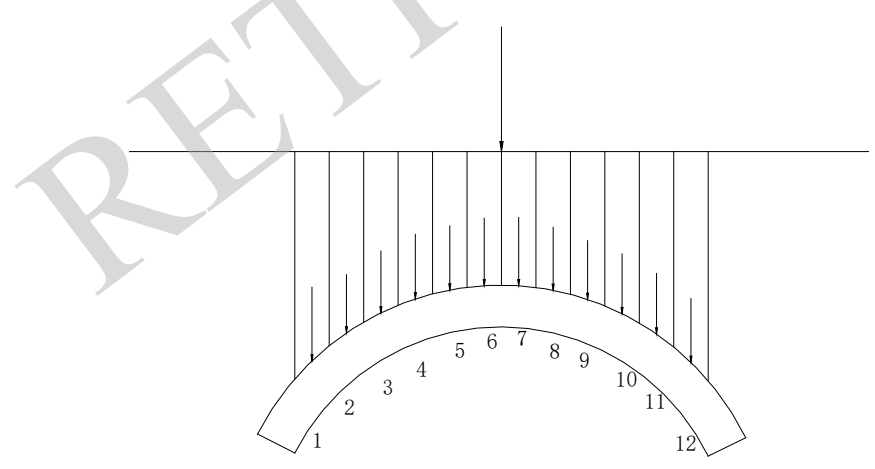

Fig. (2). Heyman calculation model.

\subsection{Failure Mode Criterion}

a) Cross section failure analysis based on fracture mechanics

As Part a of Fig. (3) shows, natural micro-cracks do little damage to the main arch, so the main arch is calculated as a three- statically-indeterminate structure. As the long-term load, weathering, and erosion goes, micro-cracks extend into long cracks until one of them develops across the whole cross section, as Part c of Fig. (3) shows. And the bridge changes into a single-hinge structure from a three-staticallyindeterminate hinge-free one, and the calculation mode is shown in Part d of Fig. (3). When a single hinge goes up to three, or as a three-hinge-statically determinate, the calculation should follow Part e of Fig. (3). However, the structure will change into a motorized system once the fourth hinge appears, and then four-hinge destruction should be the failure form and failure criterion of a stone arch bridge.

As the crack until this stage is small, the arch ring will not get enough destruction and its the mechanical mode is a three-statically-indeterminate structure while its structural microcracks extend on. Because of long-term load, weathering and erosion, the structure is then changed from a three-statically-indeterminate-hinged arch into a singlehinged arch and the calculation model is shown in the figure below; when the number of a single hinge reaches 3 , the computing model is shown in Fig. e, and then it becomes a three-hinged-statically-determinate structure system; when four hinges appear, the structure will change into a motorized system. So the four hinges are the destruction form in the main arch ring of masonry arch bridge, and it becomes the structural destruction criterion.

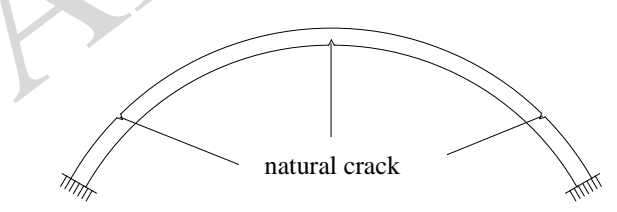

a. natural crack in the main arch ring

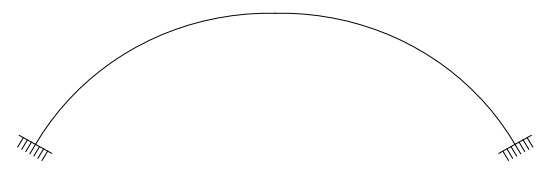

b. main arch model(three-time-statically-indeterminate structure)

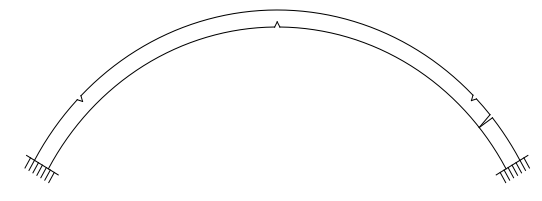

c. crack spreading to through cracks

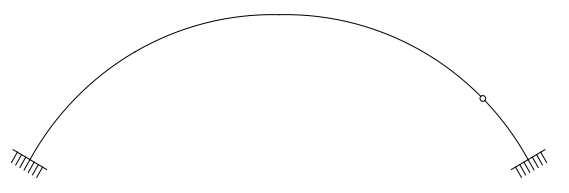

d. single hinge calculation model after through cracks appear

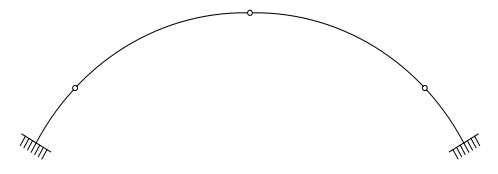

e. calculation model of three hinged statically structure

Fig. (3). Failure mode of main arch. 
As cracks develop, the fracture toughness $\mathrm{K}$ plays a decisive role. A sectional criterion is proposed to determine the safety of this cross section. The safety of section is inversely proportional to the value of $\mathrm{K}$ and the section turns unsafe once $K$ reaches the unstable state value, that's to say, an increase to the maximum value. Theoretically speaking, the system turns motorized once the fourth hinged section appears and the main arch will ultimately be destroyed. Additionally, the direction, length and density of cracks will also influence the value of a. The expression is as follows:

$a=\beta_{1} \beta_{2} \beta_{3} \beta_{4} K$

In the equation, $\beta_{1}, \beta_{2}, \beta_{3}, \beta_{4}$ represent the correction values of a regarding length, orientation, position and density of cracks. $\beta_{1}$-get from on-site ruler measurement(mm), $\beta_{2}-$ the inclination of crack position (dimensionless), $\beta_{3}$-the arch foot section, the $1 / 4$ section v the $1 / 8$ section or the cross $\operatorname{section}(\mathrm{mm}), \beta_{4}$-the number of cracks occupy the key sections(number/mm2).

b) Cross-section destruction analysis based on the external force

Before the study of the section failure, the cross-section under pressure should be considered. The probable situations are listed in Fig. (4). As load position 1 shows, the situation is the axial compressive state in which the section bears no bending moment but only under pressure coinciding with the section centroid axis. Being extremely rare in the actual stone arch bridge, it is not considered here. It is a little eccentric compression case for load position 2, so that the entire section is in a state of compression. As the load increases, the local place where compressive stress is large will be crushed, and the neutral axis will be shifted a little to the right, and the pressure area of the cross-section be reduced. Finally, concrete compressive section will be destroyed by crushing. The depth of the compressive zone is of vital importance for the structure. Load position 3 belongs to large eccentric compression, due to the large eccentricity, the far side of the section from load becomes stressed from compression and gets out of work as the limit tension comes up. As a result, crack appears in the section and the compression area shrinks. Once the compression section is not large enough to withstand the axis force of the main arch, the cross-section will be destroyed by the cracks and become a hinge.
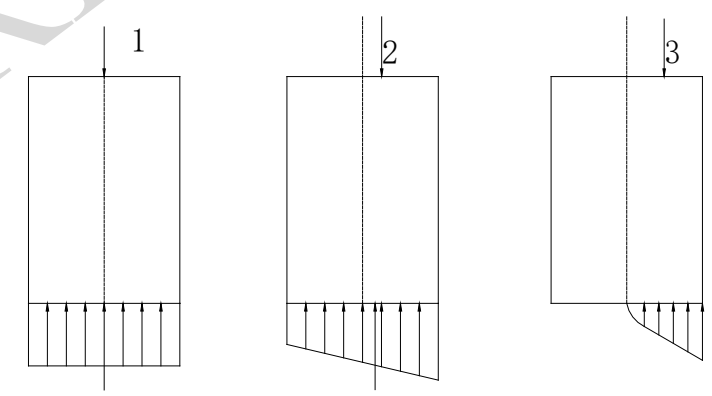

Fig. (4). Section compression.

According to the authors, plastic hinge appears in 3 forms: 1)Section failure comes without warning, because the cross section under full compression won't experience tensile cracks, and the rock under compression also belongs to brittle failure, a cross hinge will instantaneously appear; 2) Cracks brought by tension appear and develop rapidly; 3) cracks resulted from tension come up but develop with selfadjustment and, once it reaches a certain height, it stops plastic hinges appear, waiting for destruction from the compression area. As the main arch is capable of self adjustment, the third case is most probable in practical engineering.

It can be determined from the analysis above that the minimum height of compression area is the critical element to section destruction. Besides, the length, position, direction, density $\mathrm{f}$ cracks and weathering in the main arch have some influence on the destruction of section. Based on this, an equation is done as follows:

$a=\beta_{1} \beta_{2} \beta_{3} \beta_{4} \frac{r}{h} \leq[a]$

In the equation: $h$ is the arch height, $\gamma$ is the Surplus height of cross section and

$\gamma=\mathrm{h}-l, l$ is the crack height, as shown in Fig. (5).

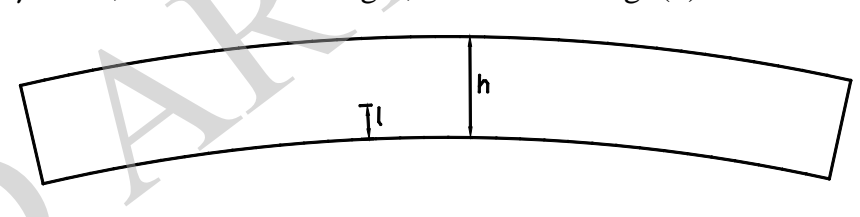

Fig. (5). Arch height and crack height.

In the equation, $[a]$ is the limit value for “a”. If it is larger than this value, the section is in insecurity. Because $\gamma+l=h$, the criterion can be expressed by crack height function, and $l$ means crack height.

$a=\beta_{1} \beta_{2} \beta_{3} \beta_{4} \frac{l}{h} \leq[a]$

As crack width $\omega$ replaces $l$, which stands for section failure criterion value, the formula changes as follows:

$a=\beta_{1} \beta_{2} \beta_{3} \beta_{4} \frac{\omega}{h} \leq[a]$

Cracks which develop perpendicularly to the arch axis should be the most dangerous ones, and those developing parallel to the arch axis are much safer. The tangle between development direction and arch axis should quantify as $\theta$. When $\theta=0$ and the length of crack is not too long, cracks won't develop any more if the direction of development is parallel to the force. In this case, the structure could be considered as safe. That is to say, $\beta_{3}=0$. But when $\theta=90^{\circ}$ and $\beta_{3}=1, \beta_{3}$ could be expressed by function with $\theta$.

$\beta_{3}=f(\theta)$

When $\theta$ ranges from 00 to 900 , a linear interpolation method is used for calculating $\beta_{3}$. 
The forming of a plastic hinge is mainly related to the size of the section and that of the section stress area, because the position of the crack has little influence on the forming of a plastic hinge, so $\beta_{2}$ has not been considered when destruction criterion $a$ is calculated.

$$
a=\beta_{1} \beta_{3} \beta_{4} \frac{\omega}{h} \leq[a]
$$

According to engineering practical bridge calculation results, structures could be put into different levels by the value rage of $a$ which is an empirical value. The rating results are shown as follow:

Safe $a \leq 1.0$

Normal $1.0<a \leq 1.5$

Harmful $1.5<a \leq 2.0$

Risky $a>2.0$

Here:

Security level- There is little disease in the bridge.

Nornal level -The structure can be used for some time though somewhat diseased.

Harmful level - The disease harms the normal bearing load of the bridge and needs detecting.

Risky level -The disease is so serious that the bridge must be reinforced at the earliest possible.

\section{EXPERIMENTAL}

\subsection{Test Purpose}

Use the model to simulate the destruction form of a real bridge so as to capture cracking and permanent deformation in the forming of hinges; then find out the extreme situation of disease and the remaining height of section as hinges appear and, accordingly as mentioned above, verify and optimize the destructive theory of stone arch bridges through test data.

\subsection{Design and Making of Scale Model}

The prototype of this scale model is a $60-\mathrm{m}$ stone arch bridge. And its length, density and elastic modulus have taken as the basic similarity coefficients. The scale model should correctly and precisely reflect the geometric relationship, rigidity and boundary condition. In this test, only the main arch has been cast and the spandrel construction simulated by the equivalent load. For better simulation, this test has been designed according to the equivalent principle. Elastic modulus E, material bulk density, geometry L, Poisson's ratio $\mu$, bending moment $\mathrm{M}$ and axial force $\mathrm{N}$, shear force $\mathrm{Q}$, concentrated force $\mathrm{P}$ as well as both cloth force $\mathrm{q}$ are the physical quantities related to the destructive mechanism. The arch and height of the span have been respectively narrowed to a ratio of 1:10 and 1:4.8 by the ultimate bearing scale model size on the basis of the similarity theory. C25 prefabricated blocks with No. 10 mortar has been selected to cast the main arch to better reflect the damage process in an actual bridge. By the similarity principle, the density of the model must be 10 times larger than that of the prototype. As such a model with its own weight can hardly reflect the original bridge load with its weight, it is necessary to counterweight the main arch with load. The size of the model main arch is shown in Fig. (6).

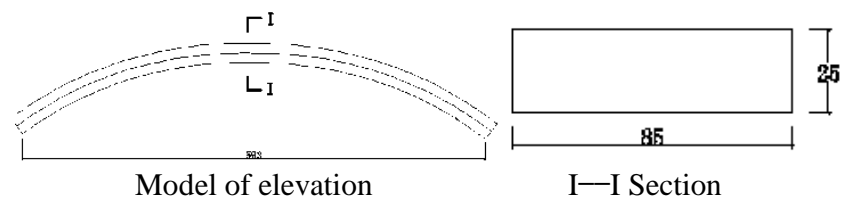

Fig. (6). Model size.

The model of the main arch ring is made of masonry in precast concrete block. Here, the precast block has four specifications to ensure the three directions of the staggered joint. We can use mortar joint to adjust the arch curvature, the bottom sizes of which are $6 \mathrm{~mm}$ and $5 \mathrm{~mm}$ respectively in longitudinal and lateral directions. The effect of the arch is shown in Fig. (7).

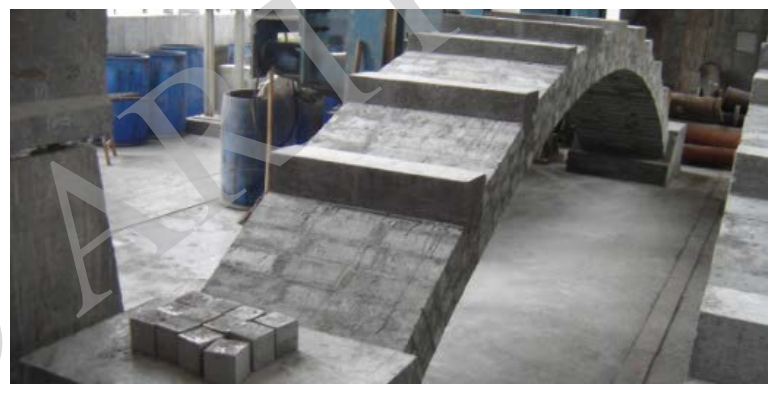

Fig. (7). Arch model.

With equal stress in the scale model and the original bridge ensured according to similar principle, the following formula can be derived:

$$
P_{M}=C_{L}^{2} P_{p}
$$

Thus, the resultant load strain relationship is:

$$
\varepsilon_{M}=\varepsilon_{p} / C_{E}
$$

PM and PP are the concentrated loads on the models and prototypes; CL is the geometry model scale, namely, the geometric similarity ratio between model LM and prototype LP; CE is the material elastic modulus ratio between the model and prototype; qM and $\mathrm{qP}$ means the distributed load degree in the model and prototype. $\Delta \mathrm{M}$ and $\Delta \mathrm{P}$ means the displacement of model and prototype. Deflection brought with distributed load is equal to that calculated by the equation above. The similarity relationship between concentrated and distributed load can be summarized from Table 1. The material used in the model and prototype is the same, that is, as the elastic modulus is equal, so when the stress or the strain is equal, the exported relationship between load and displacement should be the same.

\subsection{LOADING}

\subsubsection{Loading Principle}

a) Sticking to the principle of keeping the stress at vault and skewback equal between model and prototype. The weight of arch and the spandrel construction should be 
simulated with concentrated and uniform force, and the counterweight should be applied to by steps.

b) Sticking to the principle of keeping the ratio between moment increment and axial load increment equal with the prototype, and applying the load gradually.

\subsubsection{Loading Conditions and Steps}

When the skewback and vault are chosen to apply the most unfavorable load, there are two main parts of the load: a) the counterweight of main arch and self weight of spandrel construction; b) load applied during the test. The two kinds of load are applied in 3 work conditions. 9 load positions are set in the model, and the counterweight of the main arch and spandrel construction weight are replaced by concentrated and uniform force. The force and position of load is shown in Fig. (8).

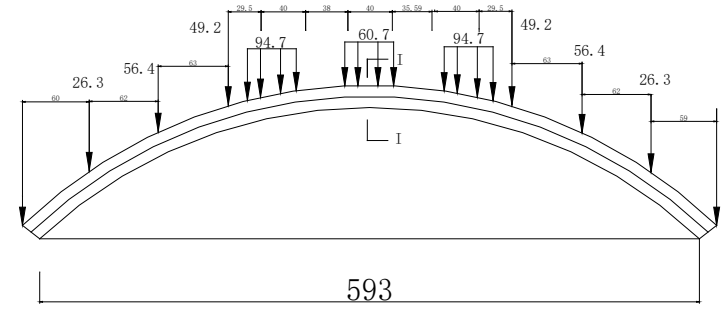

Fig. (8). Sketch map of load.

\subsubsection{Loading Arrangement}

Because of the constant dead load and the huge number of loading points, coordinate loading can't be realized by jack. So we have to use lever counterweight with a jack to apply load. Loading arrangement is shown in Fig. (9) and counterweight arrangement is shown in Fig. (10). The load value is calculated by finite element software. The specific load process is: $16 t-25 t-30 t-35 t-40 t-47 t$. (The finite element calculation result is omitted).

\section{DATA ANALYSIS}

\subsection{Data Acquisition}

Strain gauges are set at vault, skewback and two 1/4 span spots, and deflection measures are set at vault and two 1/4 span spots. Besides, one displacement meter is set at the support. See Fig. (11).

\subsection{Records of Cracks}

Occurrence of cracks as load increases also recorded, as shown in Table 2.

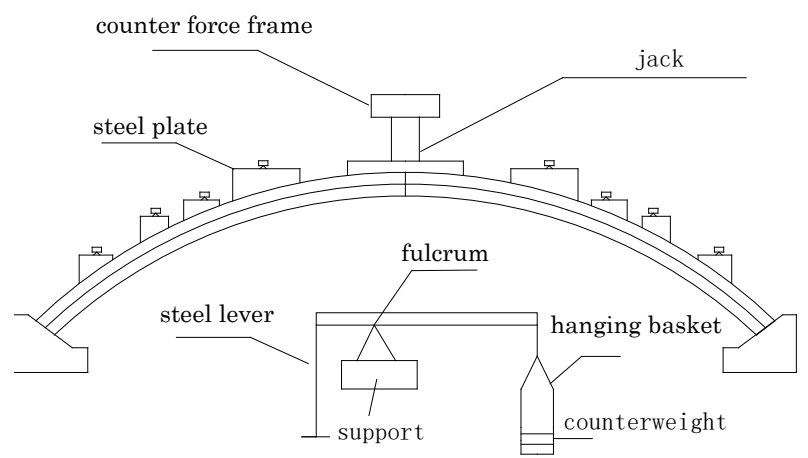

Fig. (9). Counter weight arrangement.

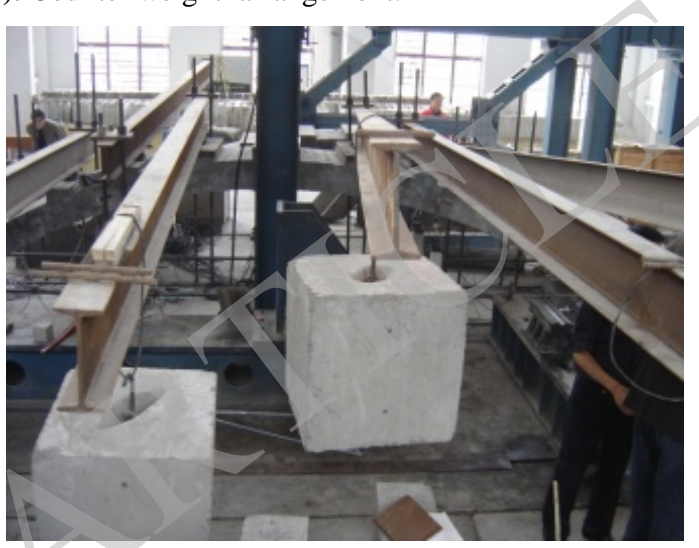

Fig. (10). Actual counterweight.

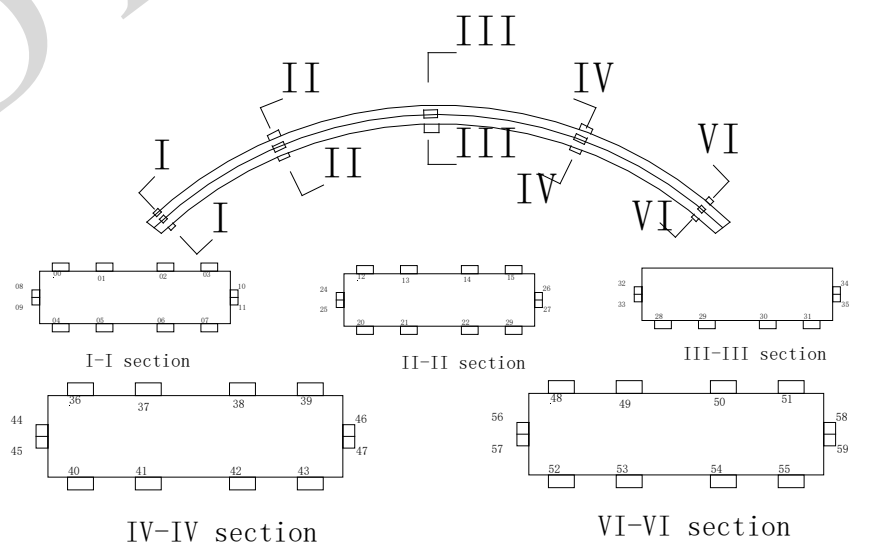

Fig. (11). Arrangement of strain gauges and deflection measures.

With the increase of load, the position of dominate crack of the main arch will be changed, so will the length, width and density of cracks accordingly. The data of dominate cracks is shown in Table $\mathbf{3}$ according to the load increase.

When the data above is put into formula (2)-(6), the derived values of $a$ under different load levels are shown in Table 4.

Table 1. Details of load conditions.

\begin{tabular}{|c|c|c|}
\hline Condition & Corresponding load & Form \\
\hline \hline Condition one & $0.6 \times($ counterweight + equivalent spandrel construction load $)$ & Centralized and distributed forces \\
\hline Condition two & Condition $1+$ failure load of vault & Centralized and distributed forces \\
\hline Condition three & Condition 1+failure load of skewback & Centralized and distributed forces \\
\hline
\end{tabular}




\section{RESULTS AND DISCUSSIONS}

As shown in Tables 1-4, cracks begin to appear when load increases to 16T, and then develop slowly. When load increases to 47T, cracks appear in greater numbers, and their length is longer. This situation coincides with the deflection and strain changes above, and two conclusions can be drawn: a) When cracks begin to appear, strain yields a mutation, though quite small. This shows that when the arch has not reached the critical failure state, it takes stress adjustment for the emergence of crakes, and the adjustment ability is quite strong and, seen on the whole, the curve develops smoothly.

b) When load increases to $47 \mathrm{~T}$, which is 2.0 times larger than the designed load, cracks appear in greater numbers.

Table 2. Development of cracks as load increases.

\begin{tabular}{|c|c|c|}
\hline Load value(T) & Case of crack appearance & Crack length \\
\hline \hline 16 & Crack no.1-no.7 & $(2 \sim 12 \mathrm{~cm})$ \\
\hline 25 & Crack no.9 & $(5.5 \mathrm{~cm})$ \\
\hline 30 & Crack no.10-nNo.11 & No.15(85cm)crack through the soffit \\
\hline 35 & Crack no.12- no.15 & Through the arch \\
\hline 40 & Crack no.17 & Four main cracks through the arch \\
\hline 47 & Crack no.18-no.24 and many other micro cracks &
\end{tabular}

Table 3. Parameters of dominate cracks for model of arch.

\begin{tabular}{|c|c|c|c|c|c|}
\hline Load Grade & No. of dominate crack & Length(cm) & Width(mm) & $\operatorname{Direction}\left({ }^{\circ}\right)$ & No. of cracks near $L / 16$ \\
\hline $16 \mathrm{t}$ & 4 & 31 & 0.25 & 90 & 2 \\
\hline $25 t$ & 4 & 31 & 0.6 & 90 & 2 \\
\hline $30 \mathrm{t}$ & 4 & & 0.6 & 86 & 3 \\
\hline $35 t$ & 4 & 40 & 1.0 & 90 & 3 \\
\hline $40 \mathrm{t}$ & 1 & 85 & 1.0 & 90 & 3 \\
\hline $47 \mathrm{t}$ & 1 & 85 & 4 & 90 & 3 \\
\hline
\end{tabular}

Table 4. Values of $a$ under different load levels.

\begin{tabular}{|c|c|c|c|c|}
\hline Load value(T) & $\beta_{1}$ & $\beta_{3}$ & $\beta_{4}$ & $a$ \\
\hline \hline $16 \mathrm{~T}(4)$ & 0.4 & 1 & 0.82 & 1.47 \\
\hline $25 \mathrm{~T}(4)$ & 0.4 & 1 & 0.82 & 0.84 \\
\hline $30 \mathrm{~T}(4)$ & 0.4 & 1 & 0.84 & 2.8 \\
\hline $35 \mathrm{~T}(4)$ & 0.5 & 1 & 0.84 & 2.53 \\
\hline $40 \mathrm{~T}(1)$ & 1 & 1 & 0.84 & 3.13 \\
\hline $47 \mathrm{~T}(1)$ & 1 & 1 & \\
\hline
\end{tabular}

Calculated, the results of criterion values of $a$ are shown in Table 5 .

Table 5. Safety evaluation in different load levels for model of main arch.

\begin{tabular}{|c|c|c|c|c|c|}
\hline Load value & $a$ & Security level & Load value & $a$ & Security level \\
\hline \hline $16 \mathrm{~T}(4)$ & 1.47 & common grade & $35 \mathrm{~T}(4)$ & 2.2 & Risk \\
\hline $25 \mathrm{~T}(4)$ & 1.86 & hidden trouble & $40 \mathrm{~T}(1)$ & 2.53 & Risk \\
\hline $30 \mathrm{~T}(4)$ & 1.87 & hidden trouble & $47 \mathrm{~T}(1)$ & Risk \\
\hline
\end{tabular}


Table 6. Safety evaluation of bridges surveyed.

\begin{tabular}{|c|c|c|c|c|c|}
\hline Bridge name & $a$ & Security level & Bridge name & $a$ & Security level \\
\hline \hline Sanyuan Bridge & 2.83 & Risk & Gongbei Bridge & 1.82 & Hidden Trouble \\
\hline Shuitian Bridge & 2.13 & Risk & Chenggong Bridge & Common Grade & Hidden Trouble \\
\hline 1.29 & Common Grade & Ranjiahe Bridge & 0.88 & Common Grade & 1.29 \\
\hline 1.2 & Common Grade & Yaziba Bridge & 0.74 & Common Grade & 1.2 \\
\hline 1.03 & Common Grade & Xingfeng Bridge & 0.57 & Common Grade & 0.95 \\
\hline 0.95 & Common Grade & Wenxi Bridge & 0.18 & \\
\hline
\end{tabular}

Strain and deflection give rise to a greater mutation. That is to say, the section of the main arch ring has much destruction, and the structure is at the threshold of destruction. The self-adjustment of the arch stress can hardly bear too much energy released from the section. When the main crack gets quite near the through crack, we can also find that the heights of several main cracks remain quite stable and, this helps us to determine that the site is close to the forming of a plastic hinge structure. This by now shows that there are four or more hinges completely formed at the arch ring, combined with the length of crack change and deflection strain change.

c) The security level of the arch bridge in this test changes with the increase of the load. According to the model calculation value a, the security level of structure is determined. When load reaches 25T, the structure is at a level of hidden danger. When load reaches 35T, the arch bridge approaches the danger level.

More than 20 diseased bridges including Sanyuan Bridge have been investigated. Formula have been put forward to calculate value a, and diseased bridges divided into different levels in detail, which is of great value for the maintenance and reinforcement for bridges in later service. The hierarchical structure of diseased bridges is shown in Table 6.

\section{CONCLUSION}

a) Combined with experiments and theoretical analysis, based on fracture evaluation the empirical formula is to be built for assessing stone arch bridge's safety grade.

b) A comparative analysis has been done between finite element calculation and model data. The trend of data proves to be coinciding with each other. Cracks in the model where appears the largest stress are got from the finite element software.

c) The model test is a good simulation of the failure process in a stone arch bridge, and the security level has been evaluated under varied loads. The test results demonstrate the calculation formula and rating standards of this paper.

d) Cracks of the model will not increase once they reach a certain height. But their width may continue, which means that a plastic hinge is formed there. e) This is a whole-process destruction model test, in which, as load increases, the appearance of cracks and development process can be captured simultaneously. The destruction process of the main arch ring can be observed as well. So crack data can be used to validate and amend the safety appraisal model criterion of a stone arch bridge, which proves that the bridge safety identification model in this research is reliable.

f) An arch ring ultimate failure form is consistent with the theoretical situation. It can be concluded that a risky section of a bridge could be estimated through theoretical calculation. It is of great research value in the future design or reinforcement of the beam and other parts. A preliminary support can be provided for increasing the life of bridge through theoretical analysis and then special treatment can be made for the risky section of a bridge. It can serve as a reference when we check the ultimate bearing capability calculation for stone bridges of same properties.

g) Application of this calculation and rating formula have been made for safety assessment to over 20 diseased bridges and proved reliable. And its important practical significance is self-evident.

\section{CONFLICT OF INTEREST}

The authors confirm that this article content has no conflict of interest.

\section{ACKNOWLEDGEMENTS}

This work was supported by the Research Fund for the Doctoral Program of Ludong University(No. LY2015021), and the Fund of National Engineering and Research Center for Mountainous Highways(No. GSGZJ-2014-03), the nature science foundation of Shandong province(No. ZR2012EE M010), and the State key laboratory of water resources and hydropower engineering science in Wuhan University(No. 2012B104).

\section{REFERENCES}

[1] W. J. Harvey, "Application of the mechanism analysis to masonry arches”, The Structural Engineer, vol. 66, pp. 5, pp. 77-84, 1998.

[2] D. K. McNeely, G. C. Archer, and K. N. Smith, "Structure analysis of old stone arch bridges", In: Second International Conference on Short and Medium Span Bridge , vol. 1, no. 1, pp. 177-192, 1986. 
[3] F. Smith, W. Harvey, and J. Vard, “Three-hinge analysis of masonry arches', The Structural Engineer, vol. 68, pp. 203-207, 1990.

[4] E. Thomas, M. Boothby, and P. J. Fanning, "Loading rating of masonry arch bridge: refinements”, Journal of Bridge Engineering, vol. 9, no. 3, pp. 304-307, 2004.

[5] Z. Orban, and M. Gutermann, "Assessment of masonry arch railway bridges using non-destructive in-situ testing methods”, The Structural Engineer, vol. 31, no. 10, pp. 2287-2298, 2009.

[6] R. Rackwitz, and B. Fiessler, "Structural reliability under combined random load sequences”, Computers and Structures, vol. 9, no. 2, pp. 20-24, 1978.

[7] M. Solla, and H. Lorenzo, "Non-destructive methodologies in the assessment of the masonry arch bridge of Traba, Spain. Engineering Failure Analysis, vol, 18, no. 2, pp. 828-835, 2011.

[8] A.J. Carr, and D.V. Jáuregui. "Structural evaluation of historic masonry arch bridges based on first hinge formation”, Construction and Building Materials, vol. 47, no. 1, pp. 569-578, 2013.

[9] Z. Orbán, and M. Gutermann, “Assessment of masonry arch railway bridges using non-destructive in-situ testing methods", Engineering Structures, vol. 31, no. 3, pp. 2287-2298, 2009.

[10] M. Solla, and J. C. Caamano, "A novel methodology for the structural assessment of stone arches based on geometric data by integration of photogrammetry and ground-penetrating radar", Engineering Structures, vol. 35, no. 1, pp. 296-306, 2012.

[11] W. E. J. Harvey, "Application of the mechanism analysis to masonry arches”, The Structural Engineer, vol. 66, no. 5, pp. 7784, 1988.

[12] L. Qingyang, “Stone Bridge Safety Appraisal Model Research", Ms Dissertation. Chongqing: Chongqing Jiaotong University, 2007.

[13] Z. Kewen, C. Bin, and Z. Jianting, "Arch permanent deformation limits of discussion”, Journal of Chongqing Traffic Institute, vol. 26, no. 1, pp. 8-9, 2007.

[14] M. Gilbert, and C. Melbourne, "Rigid-block analysis of masonry structures”, The Structural Engineer, vol. 72, no. 21, pp. 356-361, 1994.

[15] J. V. Lemos, "Discrete element modelling of masonry structures", International Journal of Architectural Heritage, vol. 1, no. 2, pp. 190-213, 2007.

[16] Z. J. Quan, and L. Qanheng, Highway Load Borne Evaluation Methods and Engineering Example. Beijing: People's Traffic Press, 2007; pp. 50-53.

[17] Y. Junjie, Similarity Theory and Structural Model Test. Wuhan: University of Technology Press, 2005, pp. 66-73.

Received: September 17, 2014

(c) Jun et al.; Licensee Bentham Open.

This is an open access article licensed under the terms of the Creative Commons Attribution Non-Commercial License (http://creativecommons.org/licenses/ by-nc/3.0/) which permits unrestricted, non-commercial use, distribution and reproduction in any medium, provided the work is properly cited. 